\title{
Evaluation of serological test of Zika in an endemic area of flavivirus in the Colombian Caribbean
}

German Arrieta ${ }^{1,2,3^{*}}$, Salim Mattar ${ }^{1,2}$, Yeneiris Villero-Wolf ${ }^{1}$, Luty Gomezcaceres ${ }^{3}$ and Amanda Doria

\begin{abstract}
The Zika virus (ZIKV) is an emerging flavivirus transmitted primarily through arthropods, endemic in Africa, Asia, and the Americas, and is considered a global threat by the World Health Organization.

Objective: To evaluate a commercial Zika virus test (IgG/lgM catalog number B815C, Biocan, Canada.

Methods: We evaluated 30 sera of patients diagnosed with Dengue, Leptospira, Malaria, Hantavirus, and Chikungunya. To establish the sensitivity of the test, two groups of sera were analyzed, the first one was patients with Zika RT-qPCR positive, and the second were patients RT-qPCR negative but with clinical suspicion of Zika.
\end{abstract}

Results: The specificity was of $23.3 \%$ (7/30), the sensitivity in acute patients with positive RT-qPCR was of $63.6 \%$, the patients with clinical suspicion of Zika the sensitivity (IgM) was of $80 \%(n=8 / 10)$. Overall sensitivity (IgM) of both groups was of $71.4 \%(15 / 21)$.

Conclusions: The test showed a low specificity to be used as a serological test in an endemic area of flavivirus infection.

Keywords: Diagnosis differential, Reagent kits, Diagnostic, Epidemiology, Arbovirus infections, Tropical medicine

\section{Introduction}

The Zika virus (ZIKV) is an emerging flavivirus transmitted primarily through arthropods, endemic in Africa, Asia, and the Americas, and is considered a global threat by the World Health Organization [1]. It has been shown that ZIKV infection during pregnancy can present neurological complications, microcephaly, intracranial calcifications, and ocular abnormalities in the fetus [2].

In the Americas, Dengue (DENV), Chikungunya, ZIKV, and other encephalitis viruses are mosquitoes borne diseases that circulate in tropical countries [3, 4]. Currently, in Latin America using only clinical criteria, DENV, ZIKV, and Chikungunya are improbable to make a definitive diagnosis and distinguish from other infections that cause similar systemic febrile illness $[5,6]$. The similarity in clinical appearances and the potential for life-threatening fetal outcomes, including microcephaly,

\footnotetext{
*Correspondence: arrietager@yahoo.es

${ }^{3}$ Grupo de Salud Pública, Corporación Universitaria del Caribe-CECAR,

Sincelejo, Sucre, Colombia

Full list of author information is available at the end of the article
}

congenital neurologic malformations, and fetal decease, and other, neurological manifestations such as GuillainBarré syndrome (GBS), emphasize the importance of accurate ZIKV diagnostics $[5,7,8]$.

ZIKV was introduced in Colombia in September 2015, causing severe public health problems that included the appearance of cases of microcephaly in newborns to mothers who had the infection during pregnancy as well as the occurrence of cases of GBS in adults and children with acute infection of ZIKV [7, 9]. Currently, Colombia has reported 108,948 cases of ZIKV, 342 cases of children with microcephaly associated with ZIKV infection and 461 cases of GBS with a history of ZIKV infection [10, 11]. Approximately $9 \%$ have been diagnosed with laboratory molecular tests [11]. Additionally, co-infections are common in the tropics, and the clinical manifestations, and even histopathological findings are comparable and challenging to make a differential diagnosis [6].

Currently, the diagnosis of ZIKV is carried out with direct methods to detect viral RNA, such as RT-qPCR and viral isolation, which are considered as the gold 
standard for the definitive diagnosis. Viral RNA detection should be performed in serum or plasma within 10 days of the onset of the disease, in whole blood within 3 weeks of onset and semen up to 3 months [12].

Real-time reverse transcription-polymerase chain reaction (RT-qPCR) is the method more used by diagnostic laboratories because of high sensitivity and reproducibly detecting targets as low as 10 copies of extracted RNA [13]. However, RT-qPCR requires trained staff and high-cost reagents. A rapid, sensitive, specific, and accessible diagnostic test for the detection of IgM and IgG antibodies to ZIKV is important in developing countries affected by arboviruses. Nevertheless, the immunologic cross-reactions of ZIKV in endemic areas with the presence of other flaviviruses represent a problem for this type of tests, because most patients than presenting clinical suspicion of ZIKV are misdiagnosed; this is due to the extensive similarity of amino acids of these flaviviruses [14].

Among the rapid tests available, there is a lateral flow chromatographic immunoassay (Biocan Tell Me Fast Zika Virus IgG/IgM Rapid Test), the test cassette consists of a pink-colored conjugate pad containing recombinant (Zika NS1 protein and envelope protein) common antigens conjugated with colloid gold and rabbit IgG-gold conjugates. A nitrocellulose membrane strip containing two test bands (T1 and T2 bands) and a control band (C). The T1 and T2 bands are pre-coated with monoclonal anti-human IgM and IgG, and the C band is pre-coated with goat anti-rabbit IgG.
This study aimed to evaluate the sensitivity and specificity of the commercially available test for the rapid detection of IgM and IgG antibodies against ZIKV in the Colombian Caribbean.

\section{Methods}

Zika Virus IgG/IgM Antibody Rapid Test, (Catalog number B815CO72916, Biocan, Canada) was assessed using the manufacturer's instructions; $25 \mu$ of patient's serum and two drops of the buffer of the kit were used, $20 \mathrm{~min}$ later results were read. To establish the sensitivity of the test, 21 sera of patients in the acute phase (1-7 days) with clinical symptoms compatible with ZIKV were used (Table 1, groups ${ }^{\mathrm{a}, \mathrm{b}}$ ). Of these 21 sera, 11 were ZIKV positive by RT-qPCR and 10 ZIKV negatives by RT-qPCRb (Table 1, groups ${ }^{\mathrm{a}, \mathrm{b}}$ ). Sera were collected between 2015 and 2016, and the specimens belonged to patients who were seen at the Clinica Salud Social of Sincelejo, Colombia, and the Biological Research Institute of the Tropic of the University of Córdoba, Colombia. As inclusion criteria patients with exanthema and at least one of the following signs or symptoms: fever, arthralgia, myalgia, and conjunctivitis were included $[15,16]$. Additionally, 12 sera of patients in convalescence stage were evaluated for the presence of IgG and IgM antibodies (Table 1, group $^{\mathrm{c}, \mathrm{d}}$ ). Of these 12 sera, 6 patients had RNA ZIKV by RT-qPCR (range $4-11$ months), and 6 patients had a high clinical suspicion of ZIKV, but negative by RT-qPCR (range 3 weeks-7 months). To establish the specificity of the test, 30 sera in acute stage collected between 2012 and 2014 (no ZIKV circulation in the Americas),

Table 1 Evaluation of ZIKV virus test lgG/IgM

\begin{tabular}{|c|c|c|c|c|}
\hline \multirow[t]{2}{*}{ Patients groups } & \multirow[t]{2}{*}{ Samples (year collection) } & \multicolumn{3}{|c|}{ Positive results of ZIKV test } \\
\hline & & $n$ & $\lg M$ & $\lg G$ \\
\hline \multirow{6}{*}{$\begin{array}{l}\text { Tropical fever groups with no } \\
\text { ZIKV circulation } n=30\end{array}$} & Dengue (2012) & 19 & 18 & 2 \\
\hline & Leptospira (2012) & 2 & 1 & 1 \\
\hline & Malaria (2012) & 3 & 1 & 1 \\
\hline & Hantavirus (2012) & 3 & 2 & 1 \\
\hline & Chikungunya (2014) & 3 & 1 & 0 \\
\hline & Total & 30 & 23 & 5 \\
\hline \multirow{5}{*}{$\begin{array}{l}\text { Epidemic ZIKV group with } \\
\text { ZIKV circulation } n=33\end{array}$} & ZIKV PCR positive ${ }^{a}(2015-2016)$ & 11 & 7 & 0 \\
\hline & ZIKV PCR negative with high clinical suspicious ${ }^{\mathrm{b}}$ (2015-2016) & 10 & 8 & 0 \\
\hline & ZIKV convalescent non-acute stage ${ }^{c}(2015-2016)$ & 6 & 5 & 0 \\
\hline & High clinical suspicious patients convalescent stage ${ }^{d}$ (2015-2016) & 6 & 5 & 0 \\
\hline & Total & 33 & 25 & 0 \\
\hline
\end{tabular}


diagnosed as Dengue $(n=19)$, Leptospira $(n=3)$, Malaria $(\mathrm{n}=3)$, Hantavirus $(\mathrm{n}=3)$ and Chikungunya $(\mathrm{n}=3)$ were analyzed; Differential routine diagnostic tests to Dengue, Leptospira, Hantavirus, Chikungunya, and Malaria thick smear were performed (Table 1).

Regarding the molecular detection of ZIKV in serum, viral RNA was extracted from $140 \mu \mathrm{l}$ of serum employing the QIAamp ${ }^{\circledR}$ Viral RNA Mini kit (QIAGEN, Hilden, Germany) following the manufacturer's instructions. In order to concentrate the virus RNA in the serum, we used Lenti- $X^{\circledR}$ concentrator (Cat 631231, Clontech). The RTqPCR was performed with the kit Zika Virus polyprotein gene, genesig ${ }^{\circledR}$ Advanced kit, (Primerdesign Ltd., United Kingdom). For each reaction, $10 \mu \mathrm{l}$ of precision PLUS OneStep $2 \times$ RT-qPCR Master Mix were added; $1 \mu \mathrm{l}$ of endogenous control primer/probe mix; $4 \mu \mathrm{l}$ of RNase/ DNase free water and $5 \mu \mathrm{l}$ of RNA template. A standard curve to quantify the viral load was carried out, $5 \mu \mathrm{l}$ RNase/DNase free water was used as a negative control. The amplification was performed using the CFX96 Touch Real-Time PCR Detection System (Bio-Rad). A serum specimen with a threshold cycle (CT) number $\leq 40$ was considered to be positive for ZIKV.

\section{Results}

The sensitivity of the IgM del test in patients with acute stage and positive RT-qPCR was of $63.6 \%(n=7 / 11$; IC $95 \%=31-81 \%)$; in patients with high clinical suspicious of ZIKV but negative qRT-PCR, the sensitivity was of $80 \%(n=8 / 10$; IC $95 \%=44-97 \%)$. The sensitivity de IgM of both groups was of $71.4 \%(n=15 / 21$; IC $95 \%=48-89 \%$ ) (Table 1 , groups ${ }^{\mathrm{a}+\mathrm{b}}$ ). The specificity of the test was of $23.3 \%$ ( $7 / 30)$; the positive predictive value and the negative predictive value was $53.8 \%$ and $36.6 \%$ respectively. IgM antibodies were detected in $90 \%$ of patients between 1 and 2 days' onset symptoms. In contrast, patients between 3 and 7 days' onset symptoms, IgM was of 50\% (5/10) (Table 2). Therefore, there was no correlation between days of clinical evolution and detection of IgM antibodies. The detection of IgM in patients in convalescent-phase ( 3 weeks-11 months, Table 1) was of $91.6 \% \%$ (11/12). IgG detection was not observable in any of the samples tested, at any stage of infection (1 day-11 months) demonstrating a null sensitivity to IgG detection. There was no correlation and dependence between viral load and detection of $\operatorname{IgM}$, in patients with high (195 viruses/ml loads) or low (0.151 viruses/ml loads) (Table 2).

Diagnosis of ZIKV infection is carried out through the detection of viral components like RNA, proteins, virus isolation, and detection of antibodies. RT-qPCR is the most common assay because of its good sensitivity and specificity [17]. However, RT-qPCR in Colombia
Table 2 Days symptoms onset of Zika patients, viral load and serology test

\begin{tabular}{|c|c|c|c|c|}
\hline \multirow[t]{2}{*}{ Code } & \multirow{2}{*}{$\begin{array}{l}\text { Days symptoms } \\
\text { onset to sampling }\end{array}$} & \multirow{2}{*}{$\begin{array}{l}\text { ZIKV qRT-PCR } \\
\text { (virus/ } \mu \mathrm{l} \text { ) }\end{array}$} & \multicolumn{2}{|c|}{ Test result } \\
\hline & & & $\lg M$ & $\lg G$ \\
\hline Am 1 & 1 & 195 & Positive & Negative \\
\hline Am 3 & 1 & 0.155 & Positive & Negative \\
\hline Am 13 & 1 & 3.12 & Positive & Negative \\
\hline Am 2 & 1 & 0 & Positive & Negative \\
\hline Am 4 & 1 & 0 & Positive & Negative \\
\hline Am 6 & 1 & 0 & Negative & Negative \\
\hline Am 8 & 1 & 0 & Positive & Negative \\
\hline Am 9 & 1 & 0 & Positive & Negative \\
\hline U 9 & 2 & 0.83 & Positive & Negative \\
\hline U 13 & 2 & 0.23 & Positive & Negative \\
\hline Am 11 & 2 & 0 & Positive & Negative \\
\hline Am 12 & 3 & 6.04 & Negative & Negative \\
\hline Am 23 & 3 & 0.19 & Positive & Negative \\
\hline Am 27 & 3 & 1.05 & Negative & Negative \\
\hline U 11 & 3 & 0.31 & Negative & Negative \\
\hline Am 15 & 3 & 0 & Negative & Negative \\
\hline Am 14 & 4 & 13.7 & Negative & Negative \\
\hline Am 16 & 4 & 0 & Positive & Negative \\
\hline Am 5 & 6 & 1.29 & Positive & Negative \\
\hline Am 10 & 6 & 0 & Positive & Negative \\
\hline Coro 20 & 7 & 0 & Positive & Negative \\
\hline
\end{tabular}

only is available in specialized laboratories. Therefore, the majority of cases are misdiagnosed or diagnosed as probable. Currently, in endemic countries mosquito's vector-borne diseases like Colombia, a feasible and serologic accuracy test to make a reliable differential diagnosis from DENV, Yellow Fever and ZIKV are decisive to implement the public health programs.

\section{Discussion}

The sensitivity of $71.4 \%$ of the present work appears to be satisfactory, especially in the acute stage of ZIKV infection. In a recent work of Zhang et al. [5], found IgG/IgA antibodies in early acute-phase ZIKV infections ( $<6$ days after symptom's onset) in Dengue-endemic regions, their assay recognized $47 \%$ of ZIKV infections with high specificity [5]. Jeong et al. [18], performed the kits Euroimmun ${ }^{\circledR}$ ELISA and Zika virus IgM/IgG Ab Rapid Test (Biocan), they found that kit Euroimmun ${ }^{\circledR}$ ELISA was able to detect the IgM from day 2 until 41 days after symptom's onset, the IgG was detected from day 8 until 52 days. In contrast, using the test IgM/IgG (Biocan) antibody detection was unsuccessful [18]. Contrary, in the present work using the test Biocan, we were able to detect IgM antibodies from the 1st day until 11 months. 
The IgG was not observable in any of the samples tested, demonstrating that the test cannot be performed in seroprevalence studies. It has not been established with precision the time of permanence of the antibodies in the serum of the patients infected by ZIKV, thus is an important include greater number of patients with past infections of ZIKV [19].

Recently, a multiplexed assay using nanotechnology gold platform for detecting IgG and IgA antibodies and IgG avidity against both ZIKV and DENV infections was developed [5]. Sera's patient from endemic flaviviruses countries of Colombia and the Dominic Republic were analyzed, the assay demonstrated IgG and IgA antibodies against ZIKV non-structural protein 1 (NS1) antigen were specific to ZIKV infection, and IgG avidity shown acute ZIKV infection and past DENV-2 infection [5]. This kind of test would be valued in endemic regions.

A specificity of $23.3 \%$ for IgM demonstrates a crossreaction of ZIKV with other flaviviruses like Dengue. We found that $94.7 \%(n=18 / 19)$ of patients with DENV were positive for Zika Biocan IgM test. The 11 analyzed samples with diagnosed Malaria, Hantavirus, Leptospirosis, and Chikungunya were also false ZIKV IgM positives, indicating previous infections with DENV because IgG antibodies were observed. Hence, the presence of DENV or Yellow Fever antibodies in a primary infection may alter the specificity of the test. Similarly, we anticipate that cross-reactivity with antibodies generated by the Yellow Fever vaccine or a future Dengue vaccine may show potential IgG positive signal for a future nonspecific ZIKV test. The design of such test addresses the issues of the prior presence or immunological memory for several other flaviviruses in the Americas. As Yellow Fever vaccinations are part of the Public Health program in Colombia, this study alerts the medical and scientific community to conduct careful testing and controls when new diagnostics tests will be introduced in the country. The low specificity of the test can be explained because Zika Biocan rapid test, as well as others commercially available kits, using a mixture of antigens NS1 (nonstructural protein 1) and ZIKV E (glycoprotein). ZIKV E has been shown in previous studies to have low specificity because it presents a high degree of similarity with the four serotypes of DENV [17]. Paul et al. [14] investigated the role of preexisting antibodies against DENV during ZIKV infection by analyzing the epitopes of human antiDENV monoclonal antibodies (MAbs) and by using an Elisa capture tested for their ability to recognize the protein of surface ZIKV E glycosylated. The results showed that the anti-DENV HMAbs strongly recognize the surface glycoprotein ZIKV E, further demonstrating by immunostaining that these HMAbs also recognize cells infected with ZIKV [14]. In contrast, in other studies that have evaluated tests using antigen mixtures with NS1, better specificity has been observed, suggesting that the non-specificity of the test is not due to NS1 use, but to the antigen ZIKV E [19-21].

\section{Conclusion}

The kit Zika Virus IgG/IgM Antibody Rapid Test needs to improve the specificity. If this assay is improved could facilitate a differential specific diagnosis of ZIKV infection and other flaviviral infections like Dengue, West Nile virus, Sant Louis encephalitis virus, and even Yellow Fever infections. The sensitivity assay could still have diagnostic value in the early acute phase (1-7 days). However, the test only can be used if it excluded the IgM active infection of Dengue in suspicious patients with ZIKV infection.

\section{Acknowledgements}

To the University of Cordoba, project sustainability groups FMVZ-01-20172018_-Project Cod. 666_Corporación Universitaria del Caribe-CECAR 2017. To Clínica Salud Social, Sincelejo (Sucre). We also thank to Lee Gehrke Ph.D and Irene Bosch Ph.D, for the donation of reagents and the critical contributions for improving the manuscript.

\section{Authors' contributions}

GA, SM and LG, conceived the study and designed its methodological aspects. YV, AD performed the tests and analyzed data and wrote the manuscript. All authors read and approved the final manuscript.

\section{Funding}

No funds were available to this study.

\section{Availability of data and materials}

No applicable.

\section{Ethics approval and consent to participate}

The research committee of the Institute of Tropical Biological Research of the University of Cordoba approved the ethics protocol, and informed consent was obtained from all patients. Patients were registered using an anonymous numeric code. The study incorporated procedures, management, and conservation of samples, and technical-administrative procedures for health research required by resolution 8430 of the Ministry of Health of Colombia, in 1993 and declaration of Helsinki for ethical and medical research in human subjects. The study was considered as minimal risk.

\section{Competing interests}

The authors declare that they have no competing interests.

\section{Author details}

${ }^{1}$ Instituto de Investigaciones Biológicas del Trópico, Universidad de Córdoba, Montería, Córdoba, Colombia. ${ }^{2}$ Clínica Salud Social, Sincelejo, Sucre, Colombia. ${ }^{3}$ Grupo de Salud Pública, Corporación Universitaria del Caribe-CECAR, Sincelejo, Sucre, Colombia.

Received: 13 June 2019 Accepted: 24 September 2019

Published online: 14 October 2019

\section{References}

1. World Health Organization. Laboratory testing for Zika virus infection: interim guidance. WHO/ZIKV/LAB/16.1. Geneva: World Health Organization; 2016. http://apps.who.int/iris/bitstream/10665/204671/1/WHO_ ZIKV_LAB_16.1_eng.pdf. Accessed 12 Mar 2018. 
2. Rasmussen SA, Jamieson DJ, Honein MA, Petersen LR. Zika virus and birth defects - reviewing the evidence for causality. N Engl J Med. 2016;374(20):1981-7.

3. Rodriguez-Morales AJ, Villamil-Gomez WE, Franco-Paredes C. The arboviral burden of disease caused by co-circulation and co-infection of dengue, chikungunya and Zika in the Americas. Travel Med Infect Dis. 2016;14(3):177-9.

4. Alvis-Guzmán N, Zakzuk-Sierra J, Vargas-Moranth R, Alcocer-Olaciregui A, Parra-Padilla D. Dengue, Chikunguña y Zika en Colombia 2015-2016. Rev MVZ Cordoba. 2017:5994-6003

5. Zhang B, Pinsky BA, Ananta JS, Zhao S, Arulkumar S, Wan H, et al. Diagnosis of Zika virus infection on a nanotechnology platform. Nat Med. 2017;23(5):548-50.

6. Mattar S, Tique V, Miranda J, Montes E, Garzon D. Undifferentiated tropical febrile illness in Cordoba, Colombia: not everything is dengue. J Infect Public Health. 2017;10(5):507-12.

7. Cuevas EL. Preliminary report of microcephaly potentially associated with Zika virus infection during pregnancy-Colombia, January-November 2016. MMWR Morb Mortal Wkly Rep. 2016;65:1409-13.

8. Mendez N, Oviedo-Pastrana M, Mattar S, Caicedo-Castro I, Arrieta G. Zika virus disease, microcephaly and Guillain-Barre syndrome in Colombia: epidemiological situation during 21 months of the Zika virus outbreak 2015-2017. Arch Public Health. 2017;75:65.

9. Sarmiento-Ospina A, Vásquez-Serna H, Jimenez-Canizales CE, VillamilGómez WE, Rodriguez-Morales AJ. Zika virus associated deaths in Colombia. Lancet Infect Dis. 2016;16(5):523-4.

10. Mattar S, Ojeda C, Arboleda J, Arrieta G, Bosch I, Botia I, et al. Case report: microcephaly associated with Zika virus infection, Colombia. BMC Infect Dis. 2017;17(1):423.

11. Instituto Nacional de Salud. Comportamientos de los eventos de vigilancia en salud pública. Boletin epidemiológico 52 de 2016; Boletin epidemiológico 52 de 2017; Boletin epidemiológico 17 de 2018. 2014. https://www.ins.gov.co/buscador-eventos/Paginas/Vista-Boletin-Epide milogico.aspx.

12. Mishra N, Caciula A, Price A, Thakkar R, Ng J, Chauhan LV, et al. Diagnosis of Zika virus infection by peptide array and enzyme-linked immunosorbent assay. mBio. 2018;9(2):e00095-18.
13. Eboigbodin KE, Brummer M, Ojalehto T, Hoser M. Rapid molecular diagnostic test for Zika virus with low demands on sample preparation and instrumentation. Diagn Microbiol Infect Dis. 2016;86(4):369-71.

14. Paul LM, Carlin ER, Jenkins MM, Tan AL, Barcellona CM, Nicholson CO, et al. Dengue virus antibodies enhance Zika virus infection. Clin Trans Immunol. 2016;5(12):e117.

15. Instituto Nacional de Salud. Protocolo de Vigilancia en Salud Pública: Enfermedad por Virus Zika (version 02). 2017. https://www.ins.gov.co/ buscador-eventos/Lineamientos/PRO\%20Zika.pdf.

16. World Health Organization. Zika virus disease: interim case definitions. 2016. https://www.who.int/csr/disease/zika/case-definition/en/.

17. Wong SJ, Furuya A, Zou J, Xie X, Dupuis AP 2nd, Kramer LD, et al. A multiplex microsphere immunoassay for Zika virus diagnosis. EBioMedicine. 2017;16:136-40.

18. Jeong YE, Cha GW, Cho JE, Lee EJ, Jee Y, Lee WJ. Viral and serological kinet ics in Zika virus-infected patients in South Korea. Virol J. 2017;14(1):70.

19. Huzly D, Hanselmann I, Schmidt-Chanasit J, Panning M. High specificity of a novel Zika virus ELISA in European patients after exposure to different flaviviruses. EuroSurveillance. 2016;21(16):30203.

20. Steinhagen $K$, Probst C, Radzimski C, Schmidt-Chanasit J, Emmerich P, van Esbroeck M, et al. Serodiagnosis of Zika virus (ZIKV) infections by a novel NS1-based ELISA devoid of cross-reactivity with dengue virus antibodies: a multicohort study of assay performance, 2015 to 2016. Eurosurveillance. 2016;21(50):30426.

21. Bosch I, De Puig H, Hiley M, Carré-Camps M, Perdomo-Celis F, Narváez CF, et al. Rapid antigen tests for dengue virus serotypes and Zika virus in patient serum. Sci Transl Med. 2017:9(409):eaan1589.

\section{Publisher's Note}

Springer Nature remains neutral with regard to jurisdictional claims in published maps and institutional affiliations.
Ready to submit your research? Choose BMC and benefit from:

- fast, convenient online submission

- thorough peer review by experienced researchers in your field

- rapid publication on acceptance

- support for research data, including large and complex data types

- gold Open Access which fosters wider collaboration and increased citations

- maximum visibility for your research: over $100 \mathrm{M}$ website views per year

At $\mathrm{BMC}$, research is always in progress.

Learn more biomedcentral.com/submissions 